Article

\title{
Evaluation of Photovoltaic Energy Saving Potential and Investment Value of Urban Buildings in China Based on GIS Technology
}

\author{
Wenjie Zhang ${ }^{1, *(\mathbb{D})}$, Fengcheng Huang ${ }^{1}$, Kai Mao ${ }^{2}$, Changqing Lin ${ }^{3}$ and Zhen Pan ${ }^{4}$ \\ 1 School of Energy and Power Engineering, Nanjing University of Science and Technology, \\ Nanjing 210094, China; huangfengcheng@njust.edu.cn \\ 2 Research Institute of Standards and Norms, Ministry of Housing and Urban-Rural Development, \\ Beijing 100044, China; maokai@mohurd.gov.cn \\ 3 School of Civil Engineering, Chongqing University, Chongqing 400044, China; linchq@sina.com \\ 4 China Academy of Building Research, Beijing 210024, China; cabrpz@163.com \\ * Correspondence: zhangwenjie001@139.com
}

Citation: Zhang, W.; Huang, F.; Mao, K.; Lin, C.; Pan, Z. Evaluation of Photovoltaic Energy Saving Potential and Investment Value of Urban Buildings in China Based on GIS Technology. Buildings 2021, 11, 649. https://doi.org/10.3390/

buildings11120649

Academic Editor: Francesco Nocera

Received: 3 November 2021

Accepted: 10 December 2021

Published: 14 December 2021

Publisher's Note: MDPI stays neutral with regard to jurisdictional claims in published maps and institutional affiliations.

Copyright: (c) 2021 by the authors. Licensee MDPI, Basel, Switzerland. This article is an open access article distributed under the terms and conditions of the Creative Commons Attribution (CC BY) license (https:// creativecommons.org/licenses/by/ $4.0 /)$.

\begin{abstract}
The environmental and energy crisis has become a problem that can not be ignored in today's world and improving the proportion of renewable energy utilization is an important way to alleviate the problem. China has begun to vigorously develop rooftop photovoltaic systems, and it is urgent to analyze the photovoltaic potential of the country. In this paper, GIS technology is used to calculate the available area of a PV system on the roof of urban buildings in China. The installed capacity and annual power generation of a PV system on the roof of urban buildings in China are further calculated, and the investment cost analysis of the buildings with a PV system is carried out. The results show that Chinese mainland city rooftop photovoltaic area has reached 3.35 billion $\mathrm{m}^{2}$. If urban roofs are used for photovoltaic power generation in China, the annual photovoltaic power generation capacity will be 672 billion $\mathrm{kWh}$, which is about $61 \%$ of the total annual electricity consumption of the whole society in 2020. On the other hand, the initial investment in the construction of an urban photovoltaic system is large, but most of them can realize the return of investment in a short period of 8-10 years. Moreover, in the effective life of the follow-up photovoltaic system, it will bring greater economic benefits, which is more than two times the initial investment. To further promote the process of social carbon peak and carbon neutrality in China, the construction of an urban photovoltaic system is very feasible.
\end{abstract}

Keywords: economic benefits; geographic information system; payback period; power generation potential; PV installed capacity; urban photovoltaic system

\section{Introduction}

According to the calculation of the United Nations Intergovernmental Panel on climate change (IPCC), in order to achieve the goal of $2{ }^{\circ} \mathrm{C}$ or even $1.5^{\circ} \mathrm{C}$ temperature control stipulated in the Paris Agreement, the world must achieve carbon neutrality by 2050 [1]. China, as the largest energy consumption and greenhouse gas emission country in the world, has taken on a major task in global energy conservation and emission reduction. Therefore, the research on China's carbon emissions is of great significance to solve the problem of world carbon emissions. In response to today's environmental and energy situation, the Chinese government proposes to reach the peak of carbon dioxide emissions around 2030 and strive to achieve carbon neutrality by 2060 .

Building energy consumption accounts for about $36 \%$ of the global terminal energy consumption, and the resulting carbon emissions account for about $40 \%$ of the total carbon emissions [2,3]. Therefore, the construction industry plays an important role in dealing with today's environmental and energy problems [4]. On the one hand, due to the acceleration 
of urbanization and the increase of residents' energy consumption demand, construction carbon emission has become a new growth area. In order to control this growth trend, increasing the production and use of on-site energy, such as photovoltaic power generation is one of the ways to achieve the goal of urban carbon neutrality [5]. On the other hand, China is rich in solar energy resources, and the annual total solar radiation received by the land surface is about $5 \times 10^{16} \mathrm{MJ}$, equivalent to $2.4 \times 10^{3}$ billion tons of standard coal, which is very suitable for the development of photovoltaic industry [6]. Now many studies have estimated and calculated the availability of building photovoltaic systems in various countries and regions. Yang Y et al. [7] explore the potential of roof-mounted solar photovoltaic projects in Sweden. Vardimon R et al. [8] used a complete set of GIS data covering the whole country to evaluate the available photovoltaic roof area in Israel. Shafique $\mathrm{M}$ et al. [9] comprehensively introduced the advantages and limitations of global photovoltaic green roofs, which provided a useful reference for the wide application of photovoltaic green roofs in the construction industry. Koo C et al. [10] developed a framework for the analysis of the potential of the rooftop PV system to achieve the net-zero energy solar buildings in terms of energy supply.

China's urbanization is developing rapidly. With the improvement of people's living standards and the needs of work and production in the city, all kinds of energy consumption of urban buildings are increasing year by year. In most urban buildings, there are many idle space resources on the roof, and there are considerable solar energy resources, which are very suitable for the installation of a photovoltaic system. Therefore, the urban building roof photovoltaic system has become one of the main application forms of urban distributed photovoltaic system construction. At present, China's photovoltaic policy is also continuously promoting the construction of roof distributed photovoltaic. On 20 June 2021, the National Energy Administration officially issued the notice on submitting the pilot scheme of a roof distributed photovoltaic development in the whole county (city, district) [11]. It planned to organize and carry out the pilot work of promoting the development of roof distributed photovoltaics in the whole county (city, district) nationwide, which has received a positive response from the provincial governments [12]. At present, relevant studies [13] have analyzed and counted the overall photovoltaic application potential in rural China. In addition, some related studies have analyzed and calculated the photovoltaic potential of Chinese cities. Shen X et al. [14] analyzed the potential of solar energy in Wuhan's urban environment based on the function and type of blocks. Yue C D et al. [15] combines Taiwan's solar resource assessment with land use analysis, considering the potential and limitations of local land use conditions for solar energy development. From the aboverelated research status, it can be found that most of the existing research on photovoltaic utilization of urban buildings in China focuses on the photovoltaic application potential of a specific city, while there is less research on the overall photovoltaic application potential of cities in China. Nowadays, China is vigorously promoting the application of building photovoltaic systems $[11,12,16]$. China urgently needs relevant data on the potential status of urban photovoltaic applications throughout the country for urban photovoltaic construction planning. Based on the above purposes, China urgently needs relevant data on the national urban photovoltaic application potential for urban photovoltaic construction planning. Based on the above purposes, the study combined the GIS technology with the building area data of the statistical yearbook to obtain the data of the Chinese mainland building roofing and building facade area. Based on the above data, the potential of PV applications in Chinese mainland cities are calculated and analyzed, and the economic application of PV Applications in city buildings are analyzed. The research calculates the application potential and economic value of roof photovoltaic in urban buildings in China. The calculation results can reflect the importance of the urban photovoltaic system for the construction of solar energy in China's future goal of "carbon peaking and carbon neutralization". The research results can, to a certain extent, increase the confidence and tendency of the Chinese government in the construction of urban photovoltaics, and further 
promote the development of urban building photovoltaics in Chinese cities, to accelerate the pace of China's realization of "carbon peaking and carbon neutralization".

\section{Methodology}

In this study, the shape area statistical calculation function of ArcMap 10.6 in vector ArcGIS series software was used to process the building plane vector map of the main urban area of each typical city. The building vector map [17] of each typical city is in SHP format, including the building outline of each city and the corresponding building height information. The area and floor data of each city in ArcMap 10.6 software were calculated and the roof area and elevation area of Chinese mainland typical city was calculated. Then, according to the relationship between the urban area of each typical city and its corresponding province city, the roof area and facades of buildings in various provinces and cities in mainland China were obtained. According to the corresponding calculation formula, the optimal installation inclination angle and the optimal installation spacing of each province and city were calculated, and then the effective roof photovoltaic power generation area of each province and city was calculated. We calculated the city's photovoltaic power generation potential based on the effective rooftop photovoltaic power generation area of each province, that is, the annual installed capacity of the city's rooftop photovoltaic and the total annual power generation, and finally estimated the investment and income after the installation of photovoltaic on the city's rooftops and analyzed its economic benefits. An overview of the methods used in this study is shown in Figure 1.

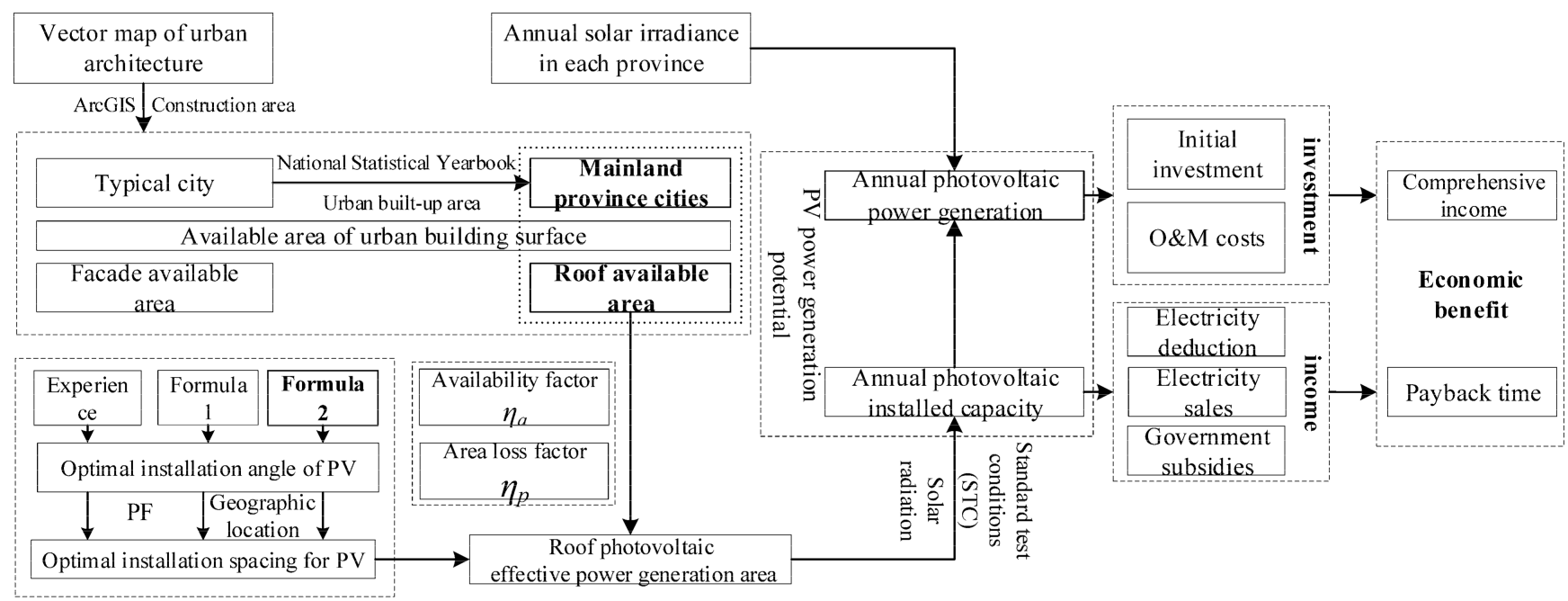

Figure 1. Overview of the methods used in paper.

\section{Photovoltaic Potential and Economic Analysis of Urban Buildings}

\subsection{Solar Radiation Resources}

\subsubsection{Spatial Distribution of Solar Energy Resources in Chinese Mainland}

The Chinese mainland is vast in territory and has many landforms. Therefore, the distribution of solar energy resources is uneven in all provinces of the mainland. China's solar energy resources are mainly concentrated in the western region. The Qinghai Tibet Plateau has the most solar radiation resources because of its low latitude, high terrain, few clouds and thin air. The average annual solar radiation is more than $7000 \mathrm{MJ} / \mathrm{m}^{2}$. The provinces in this region mainly include Western Tibet, Southeast Xinjiang, western Qinghai and Northern Gansu. Secondly, the highest solar radiation value is in Northwest and North China, and the annual solar radiation value is about $6000 \mathrm{MJ} / \mathrm{m}^{2}$. However, due to the low terrain and the influence of air humidity and other related factors, the solar radiation value of the Sichuan Basin is at a low level. 
From the overall situation of solar energy resources distribution in the Chinese mainland, the most abundant solar radiation area is located in the southwest and northwest of China.

\subsubsection{Statistics of Solar Energy Resources in Different Provinces}

Because of the uneven distribution of solar radiation resources in mainland China, Wang Bingzhong and others, based the annual total solar radiation distribution in Chinese mainland cities, divided China into four solar energy resources zones, namely, resource rich area, richer source area, general resource area and resource poor area, as shown in Figure 2.

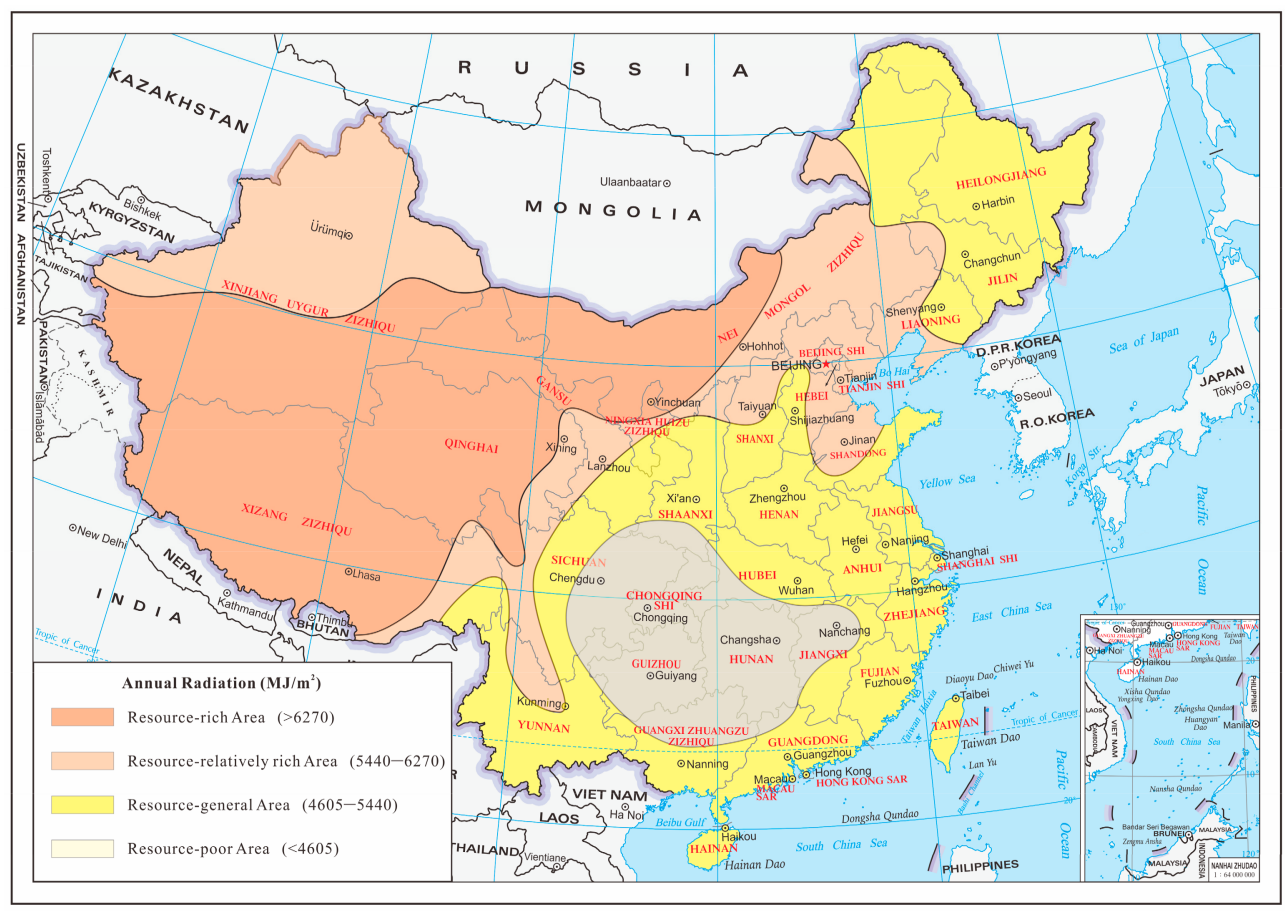

Figure 2. Regionalization of China's solar radiation resources.

It can be seen from Figure 2 that many provinces span multiple solar radiation resource belts, which is not easy to determine the solar radiation resources of a single province. In the existing research, there is also a lack of statistics on the annual total solar radiation resources of all provinces and cities in China. Therefore, this section takes the average radiation value of each solar radiation resource zone as the standard and calculates the average annual solar radiation resources of each province according to the area proportion of different radiation zones in a single province. According to the above method, the solar radiation resources of various provinces and cities are obtained, as shown in

\subsection{Available Area of Urban Building Surface}

The height of urban buildings is high. In order to minimize the impact of shadow on the power generation efficiency of photovoltaic modules, the ideal location for the installation of photovoltaic modules is the roof. On the other hand, because the roof area of urban buildings is smaller than the building volume, the building facade can be used properly to increase the advantage of photovoltaic power generation.

Therefore, in order to judge how much usable area of building surface exists in Chinese cities, it is necessary to make statistics on the roof area (which can be regarded as the floor area) and facade area of buildings in various cities in China. According to the previous literature, some studies [18-20] use the urban building density combined with the building area to estimate the building area and facade area of many cities, and the estimation error 
is large; Other studies [14,21-24] deal with and analyze the remote sensing satellite map of cities, that is to say, the method of GIS (Geographic Information System) is used for statistical calculation, but the calculation workload of this method is large. There are nearly 700 large and small cities in China, so it is difficult to carry out nationwide statistics with this method. Figure 3.

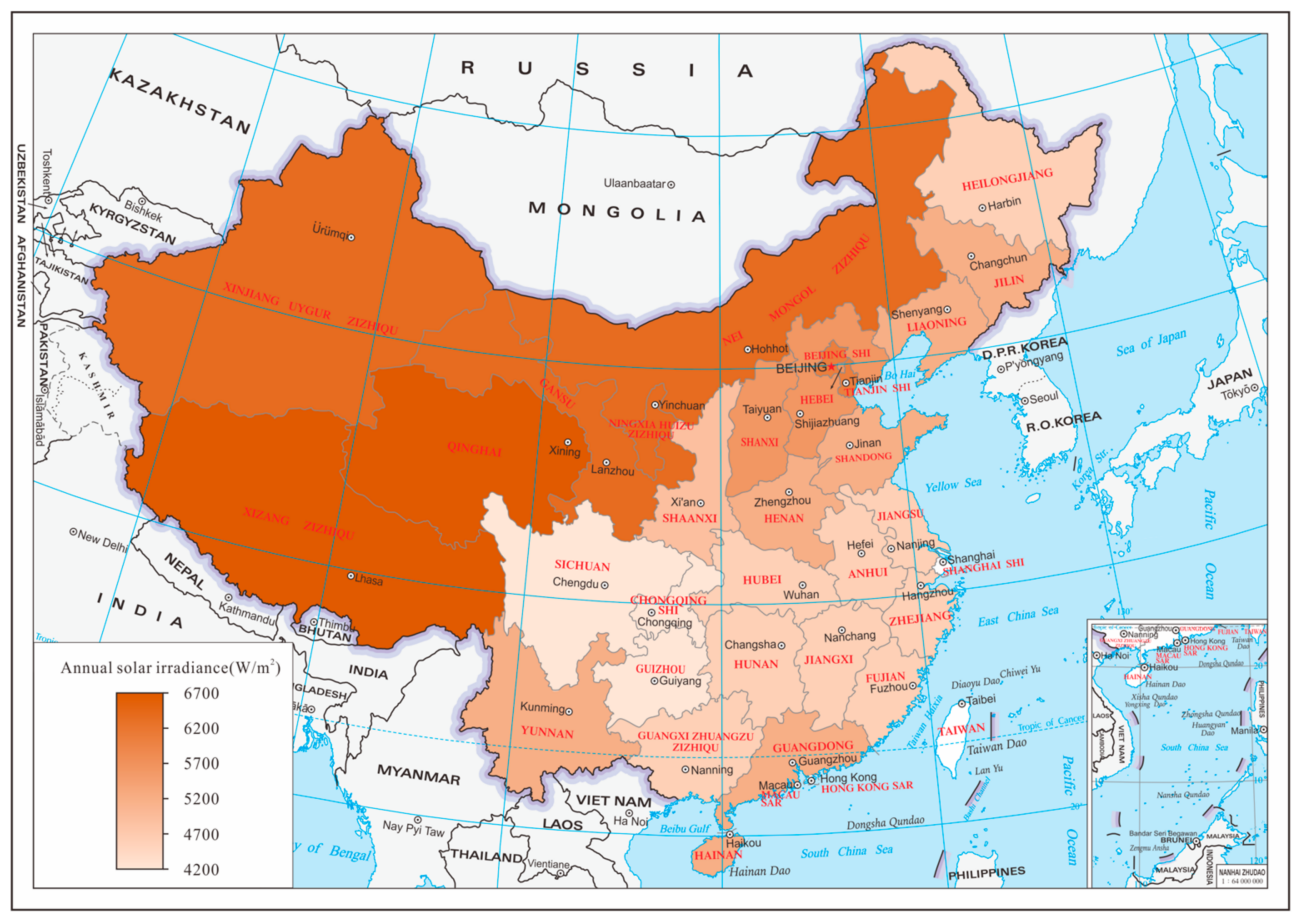

Figure 3. Distribution of solar radiation resources in various provinces.

This paper combines the above two methods to balance the advantages and disadvantages between them. Firstly, the typical cities in China's provincial administrative regions are selected, and the statistical calculation of urban building roof area and facade area is carried out by using the GIS analysis method, then the relationship between the built-up area of cities in different provinces and cities is obtained. Based on the above calculation results of typical cities, the roof area and facade area of cities in China are estimated.

\subsubsection{Available Area of Building Surface in Typical Cities of Each Province}

In this section, 23 provinces, the capital cities of five autonomous regions and four municipalities directly under the central government of China are selected as typical cities of each provincial administrative region. We collected the vector map of the building contour [17] of the main urban area of each typical city after certain processing, including the building storey information. The vector map of the building contour of Beijing is shown in Figure 4.

The ArcGIS map processing software is used to calculate and process the building contour vector map of each typical city which contains the building storey information according to the following steps.

(1) The area and perimeter of each building contour in a typical city map are calculated statistically;

(2) The area of all building blocks in the map calculated in the previous step is accumulated to obtain the building area of the typical city, namely the building roof area;

(3) After reading the building layers corresponding to each building block in the building outline map of a typical city by ArcGIS map processing software, assuming that the floor height of each building is $3 \mathrm{~m}$, the building height corresponding to each building block is calculated. 
(4) Multiply the perimeter of each building block in the map obtained in step (1) by the building height of the corresponding building block obtained in step (3) to calculate the elevation area of each building outline block in the map;

(5) The building elevation area of the typical city can be calculated by adding up the elevation area corresponding to each building block on the building outline map.

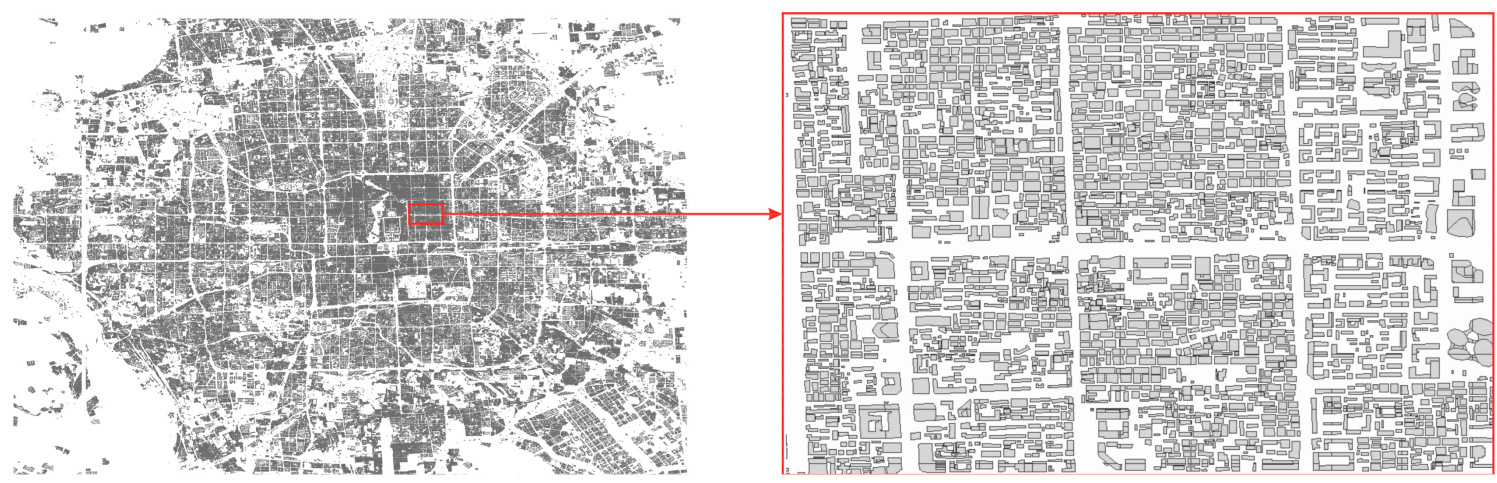

Figure 4. Outline map of buildings in Beijing.

According to the above calculation steps, the roof area and facade area of each typical city can be calculated. The statistics of buildings in typical cities are shown in Table 1.

\subsubsection{Usable Area of Building Surface}

In the previous section, this paper uses GIS technology to count the building roof area and building facade area of each typical city. The city's total area of surface area can be estimated by the relationship between the built-up area of each province and the corresponding typical cities. The specific steps are as follows:

(1) The data of the provincial statistical yearbook of each province and the Municipal Statistical Yearbook of each typical city are statistically sorted, and the urban built-up area data [25] of each province and typical city are obtained.

(2) According to the proportional relationship between the urban built-up area of each province and its corresponding typical cities in the previous step, combined with the data calculated in Section 3.1, the overall situation of urban building roof area and facade area of each province is calculated, as shown in Figure 5.

According to Figure 5, the surface area of the city's buildings in each provincial administrative unit is calculated. The total roof area of Chinese mainland cities is 6.90 billion $\mathrm{m}^{2}$ and the building facade area is 19.87 billion $\mathrm{m}^{2}$. It can be seen that in urban buildings, the area of the building facade is nearly three times that of the roof, which has great potential. However, the current installation of photovoltaic modules on building facades needs to consider the problems of building shading and daylighting, and the density of urban buildings, the building facades are seriously shielded from each other, and the installation of photovoltaic modules has greater limitations. The following only discusses the situation of building roof photovoltaic systems.

\subsection{The Area of PV Installed in Urban Building Roof}

The area of PV modules installed on the building roof is affected by many factors, such as the installation angle of PV modules, the installation distance between PV modules and the idle area of the roof. In order to improve the power generation efficiency of photovoltaic modules as much as possible, it is necessary to determine the best installation angle and the best installation spacing of photovoltaic modules in each province in this section. 
Table 1. Construction area of typical cities.

\begin{tabular}{|c|c|c|c|c|}
\hline City & $\begin{array}{c}\text { Latitude } \\
\left({ }^{\circ}\right)\end{array}$ & $\begin{array}{c}\text { Area of } \\
\text { Building Roof } \\
\left(\times 10^{6} \mathrm{~m}^{2}\right)\end{array}$ & $\begin{array}{l}\text { Perimeter of } \\
\text { Building Roof } \\
\left(\times 10^{3} \mathrm{~m}\right)\end{array}$ & $\begin{array}{c}\text { Area of } \\
\text { Building Facade } \\
\left(\times 10^{6} \mathrm{~m}^{2}\right)\end{array}$ \\
\hline Haikou & 19.17 & 20.85 & 4404.84 & 48.83 \\
\hline Guangzhou & 22.86 & 162.31 & $28,485.95$ & 360.24 \\
\hline Nanning & 23.64 & 33.63 & 6747.72 & 109.90 \\
\hline Kunming & 25.19 & 32.82 & 6655.82 & 220.76 \\
\hline Fuzhou & 25.93 & 29.72 & 5406.67 & 86.14 \\
\hline Guiyang & 26.92 & 21.50 & 4090.10 & 73.55 \\
\hline Nanchang & 27.28 & 17.32 & 3402.70 & 44.38 \\
\hline Changsha & 27.38 & 46.34 & 9266.99 & 171.69 \\
\hline Hangzhou & 29.36 & 61.49 & $11,683.38$ & 200.73 \\
\hline Chengdu & 30.18 & 106.43 & $20,059.58$ & 360.98 \\
\hline Chongqing & 30.19 & 65.21 & $11,472.57$ & 233.61 \\
\hline Wuhan & 31.21 & 85.55 & $16,090.66$ & 244.79 \\
\hline Shanghai & 31.25 & 253.15 & $48,170.54$ & 756.98 \\
\hline Lhasa & 31.63 & 8.59 & 2105.54 & 13.89 \\
\hline Hefei & 32.16 & 51.82 & $10,064.33$ & 181.04 \\
\hline Nanjing & 33.04 & 68.61 & $15,716.20$ & 220.76 \\
\hline Zhengzhou & 33.88 & 70.30 & $13,172.33$ & 199.86 \\
\hline $\mathrm{Xi}^{\prime}$ an & 35.64 & 89.31 & $15,758.83$ & 248.47 \\
\hline Jinan & 36.38 & 57.80 & $10,747.60$ & 155.43 \\
\hline Yinchuan & 37.31 & 8.61 & 1701.85 & 21.47 \\
\hline Lanzhou & 37.57 & 23.36 & 4305.66 & 49.84 \\
\hline Taiyuan & 37.64 & 36.22 & 7107.44 & 82.13 \\
\hline Shijiazhuang & 39.32 & 45.73 & 8856.75 & 132.58 \\
\hline Tianjin & 39.41 & 78.64 & $15,189.70$ & 188.18 \\
\hline Beijing & 40.24 & 166.71 & $30,447.49$ & 377.72 \\
\hline Shenyang & 41.08 & 93.98 & $17,709.32$ & 211.36 \\
\hline Urumqi & 41.77 & 23.52 & 4584.09 & 119.17 \\
\hline Changchun & 43.58 & 66.12 & $11,691.43$ & 138.22 \\
\hline Hohhot & 45.39 & 15.81 & 3169.13 & 36.68 \\
\hline Harbin & 48.48 & 45.17 & 8210.48 & 128.87 \\
\hline Xining & 64.24 & 11.66 & 2443.30 & 32.99 \\
\hline
\end{tabular}

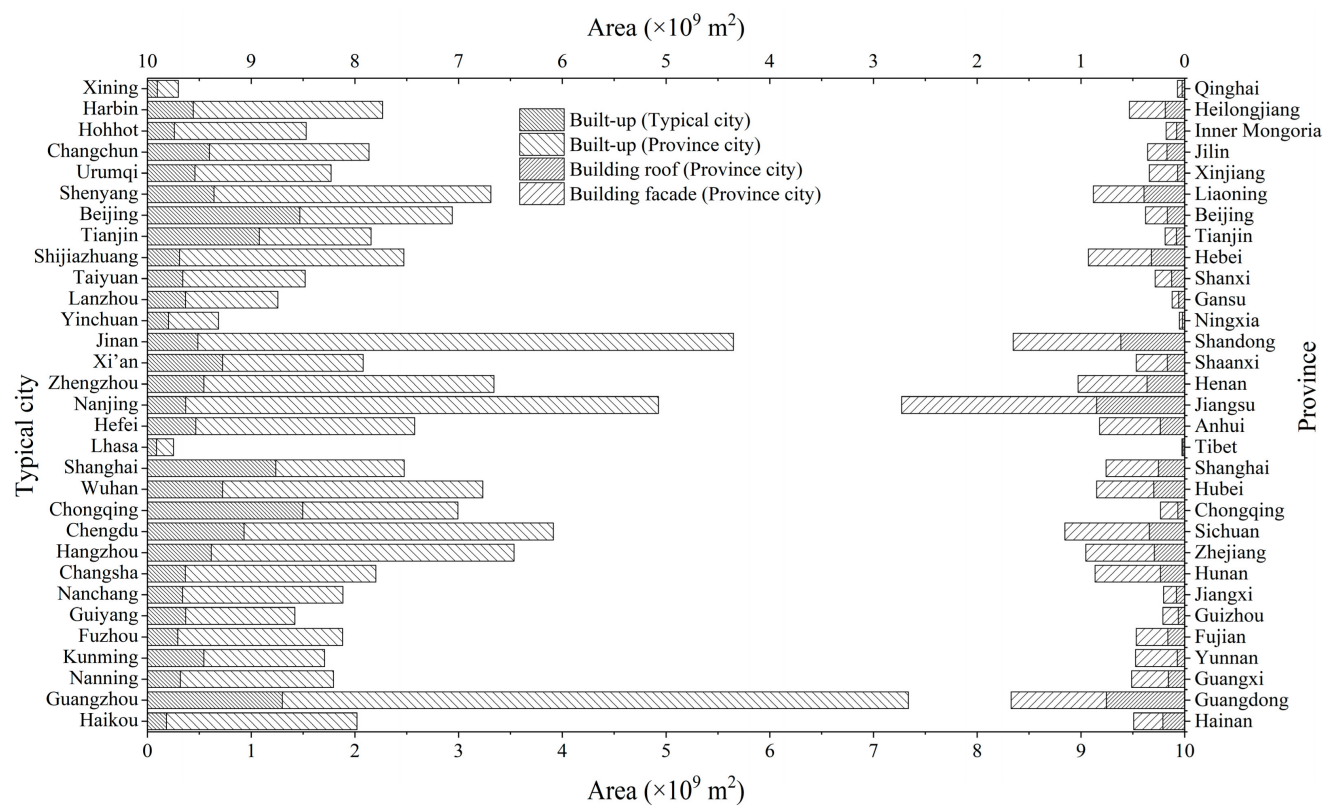

Figure 5. Construction area of each province. 


\subsubsection{Optimum Installation Angle of Roof Photovoltaic}

Chinese mainland provinces have different geographical locations and different climatic conditions. Therefore, the best installation angle of PVs in each province should be calculated separately. The most important factor affecting the best installation angle of photovoltaics is the latitude of the installation site. Many methods for calculating the best installation angle are obtained based on this. The following introduces several methods for calculating the best installation angle of photovoltaics.

The first method is to find out the best installation angle of photovoltaics in each typical city according to the experience table of local photovoltaic installation angles obtained by some organizations and divide different best installation angle intervals for different provinces. From this, we can get the best installation angle of photovoltaics in each province to be calculated in this section.

The other method is to calculate the best installation angle of photovoltaics by using the calculation formula verified in some studies. Most of these formulas simplify the calculation of the optimal installation angle of photovoltaics to the relationship related to latitude. This section mainly takes two different formulas as examples.

(1) First of all, the first type of formula [26] is relatively simple, and the optimal installation angle of photovoltaics varies linearly with latitude, but the coefficient of the formula will change in different latitudes, as shown below.

$$
\left\{\begin{array}{c}
\beta_{\mathrm{opt}}=0.908 \varphi+0.73^{\circ}, \varphi \leq 65^{\circ} \\
\beta_{\mathrm{opt}}=0.306 \varphi+32.40^{\circ}, \varphi>65^{\circ}
\end{array}\right.
$$

where, $\varphi$ is the geographic latitude, where is the average latitude of each province.

Because Chinese mainland city latitude is below $65^{\circ}$, therefore, only the first formula of the formula is used to calculate.

(2) The other kind of formula is more complex, and the accuracy of the best installation angle of photovoltaics is higher, and the formula has a wide range of applications. Formula (2) has been modified from the original Formula [7], as shown in the following.

$$
\beta_{\mathrm{opt}}=1.3793+\varphi(1.2011+\varphi(-0.014404+\varphi 0.000080509))
$$

According to the above experience table and the two formulas, the optimal PV tilt angle of each province is shown in Figure 6.

It can be seen from Figure 6 that the change trend of the best PV installation angle and latitude of each province is not the same by using the quick look-up table, and the $\mathrm{PV}$ installation angle of provinces with different latitudes also takes the same value. This is because the main function of the quick look-up table for the best installation angle of photovoltaics is to provide a reference value for the installation value of photovoltaics in various places. For the convenience of installation, the recommended value will give an angle that is easy to realize as far as possible. When the difference between the best installation angles of some provinces and cities is small, it is easy to get the same angle. The best installation angle of photovoltaics is calculated by two groups of formulas, because it is a function of latitude, so the change trend of the two groups of curves calculated by the formulas is basically consistent with the change of latitude. In addition, it can be seen from Figure 2 that the optimal installation angle of photovoltaics calculated by Formula (2) is smoother than Formula (1).

\subsubsection{Optimal Installation Spacing of Roof Photovoltaic}

The space available on the roof is small. In order to improve the area utilization of the roof as much as possible on the premise of ensuring that the photovoltaic panels are not sheltered from each other, it is necessary to calculate the optimal installation spacing of photovoltaic panels when the size and installation angle of photovoltaic panels are determined. The installation spacing of different PV modules is related to many factors, 
such as the installation angle of PV modules, the size of PV panels, the solar altitude angle and the local latitude. Therefore, this paper uses the packing factor (PF) to describe the position relationship of a photovoltaic array on the roof. The fill factor pf defines the proportion of the total ground area of the PV array and the installation of the PV array, and also considers the mutual shielding effect under the influence of the above different factors and determines the spacing in each case. The installation position relationship of a photovoltaic array is shown in Figure 7.

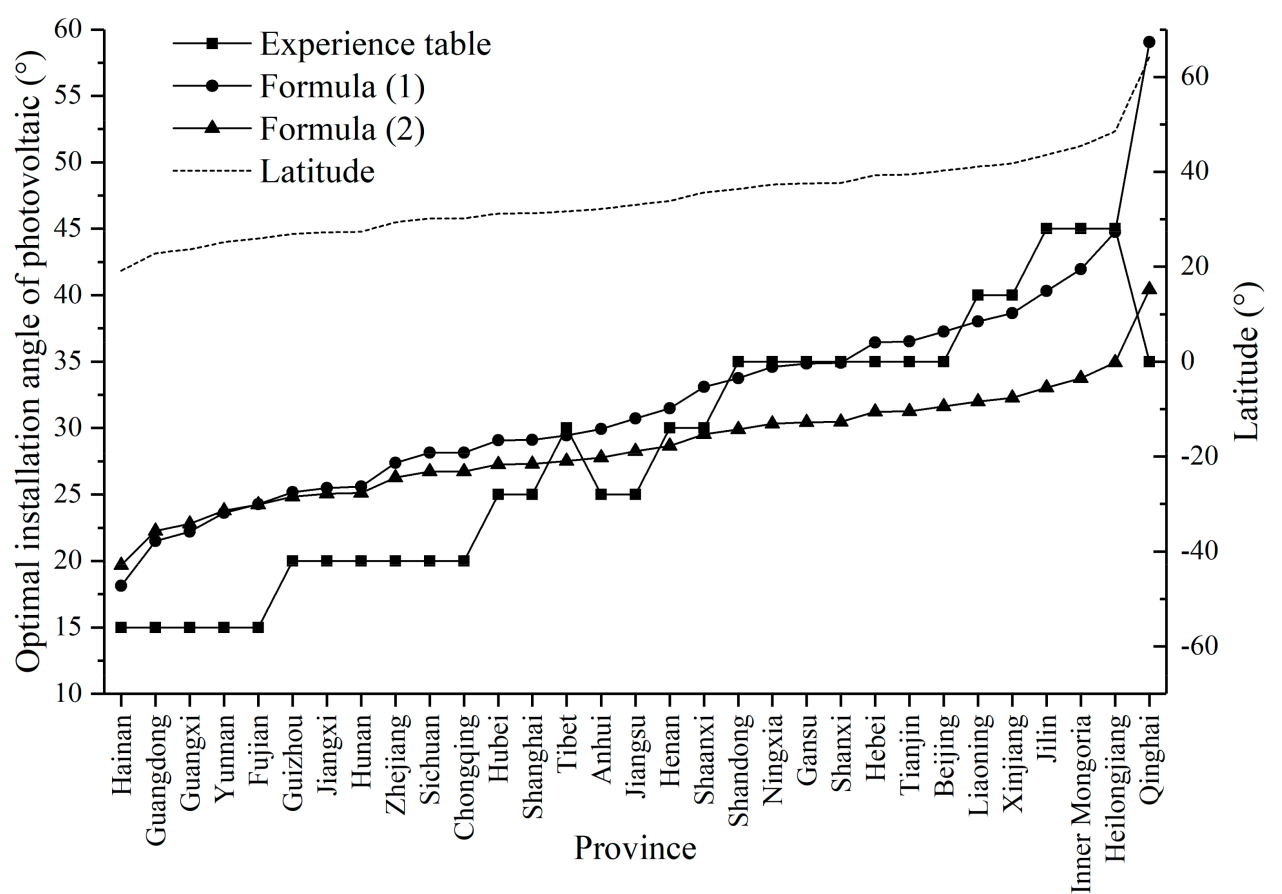

Figure 6. Comparison of the best installation angle of cities in different provinces.

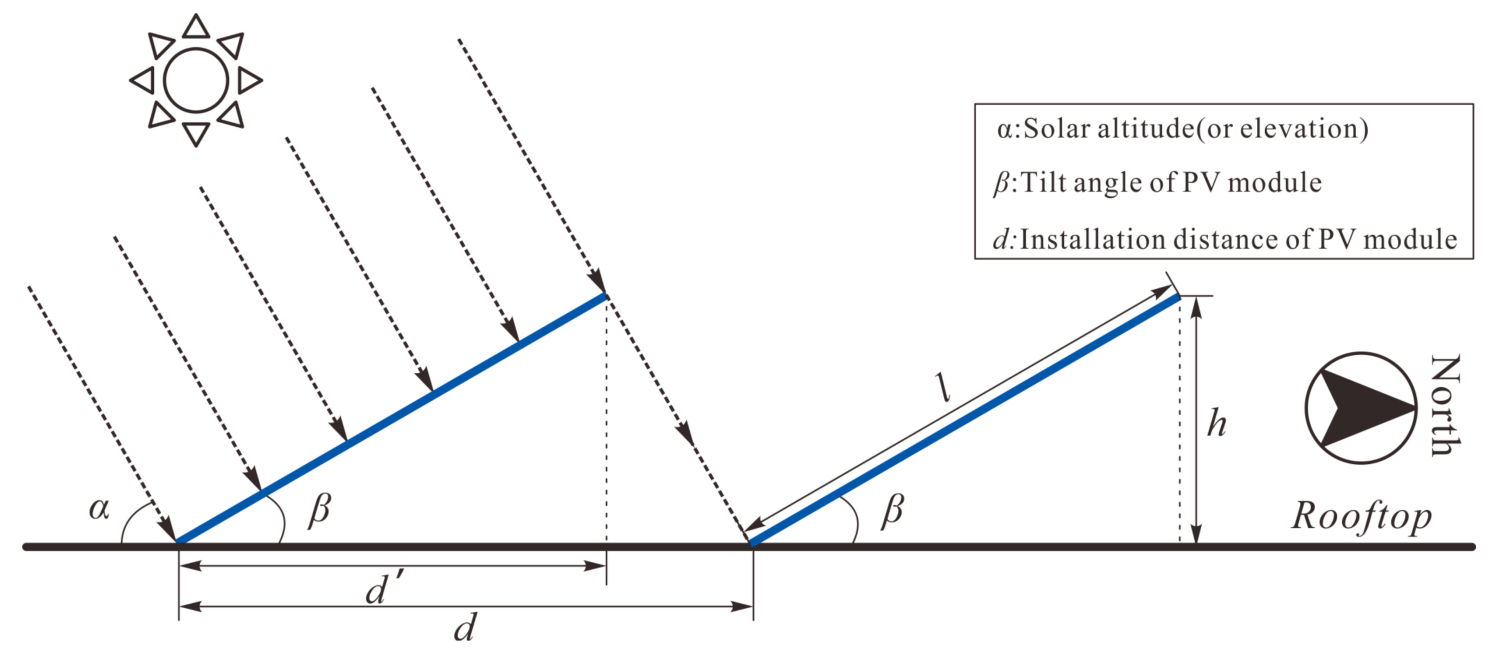

Figure 7. Schematic diagram of photovoltaic installation spacing.

According to the location relationship in Figure 7 and the definition of filling factor $\mathrm{PF}$, the filling factor PF can be obtained, and its calculation formula [27] is shown in Formula (3).

$$
P F=\frac{l}{d}=\left(\cos \beta+\frac{\sin \beta}{\tan \alpha} \cos \gamma\right)^{-1}
$$


The calculation formula of the spacing $d(\mathrm{~m})$ of photovoltaic panels can be obtained by deformation derivation of this formula, as shown in Formula (4):

$$
d=\left(\cos \beta+\frac{\sin \beta}{\tan \alpha} \cos \gamma\right) l
$$

where $l$ is the width of the photovoltaic panel $(\mathrm{m}) ; \beta$ is the installation angle of the photovoltaic panel; $\alpha$ is the solar altitude angle; $\gamma$ is the azimuth of the sun.

In Formula (4), the calculation of parameters, such as $\alpha$ and $\gamma$ are all related to local geographical factors, as shown in Formulas (5) and (6):

$$
\begin{gathered}
\cos \alpha=\sin \delta \sin \varphi+\cos \delta \cos \varphi \cos \omega \\
\cos \gamma=\frac{\sin \alpha \sin \varphi-\sin \delta}{\cos \alpha \cos \varphi}
\end{gathered}
$$

where $\omega$ is the time angle; $\delta$ is the declination angle; $\varphi$ is the local latitude.

Substituting the above Formulas (5) and (6) into Formula (4) to obtain Formula (7) as follows:

$$
d=l\left(\cos \beta+\sin \beta\left(\tan \varphi-\frac{\sin \delta}{\cos \varphi \sin (\arccos (\sin \delta \sin \varphi+\cos \delta \cos \varphi \cos \omega))}\right)\right)
$$

From Formula (7), it can be seen that the spacing $\mathrm{d}(\mathrm{m})$ of photovoltaic panels is only related to the inclination of photovoltaic panels and the geographical location parameters. Therefore, just substituting the optimal photovoltaic installation inclination calculated in Section 3.3.1 and the geographic information of the photovoltaic installation location into Formula (7), you can get the optimal photovoltaic installation spacing on the roof of different cities. In this section, the optimal installation inclination angles of the three photovoltaic panels calculated in Section 3.3.1 and the geographic information of each province are substituted into Formula (7) for calculation, and the optimal installation spacing of roof photovoltaic panels in different provinces is obtained as shown in Figure 8.

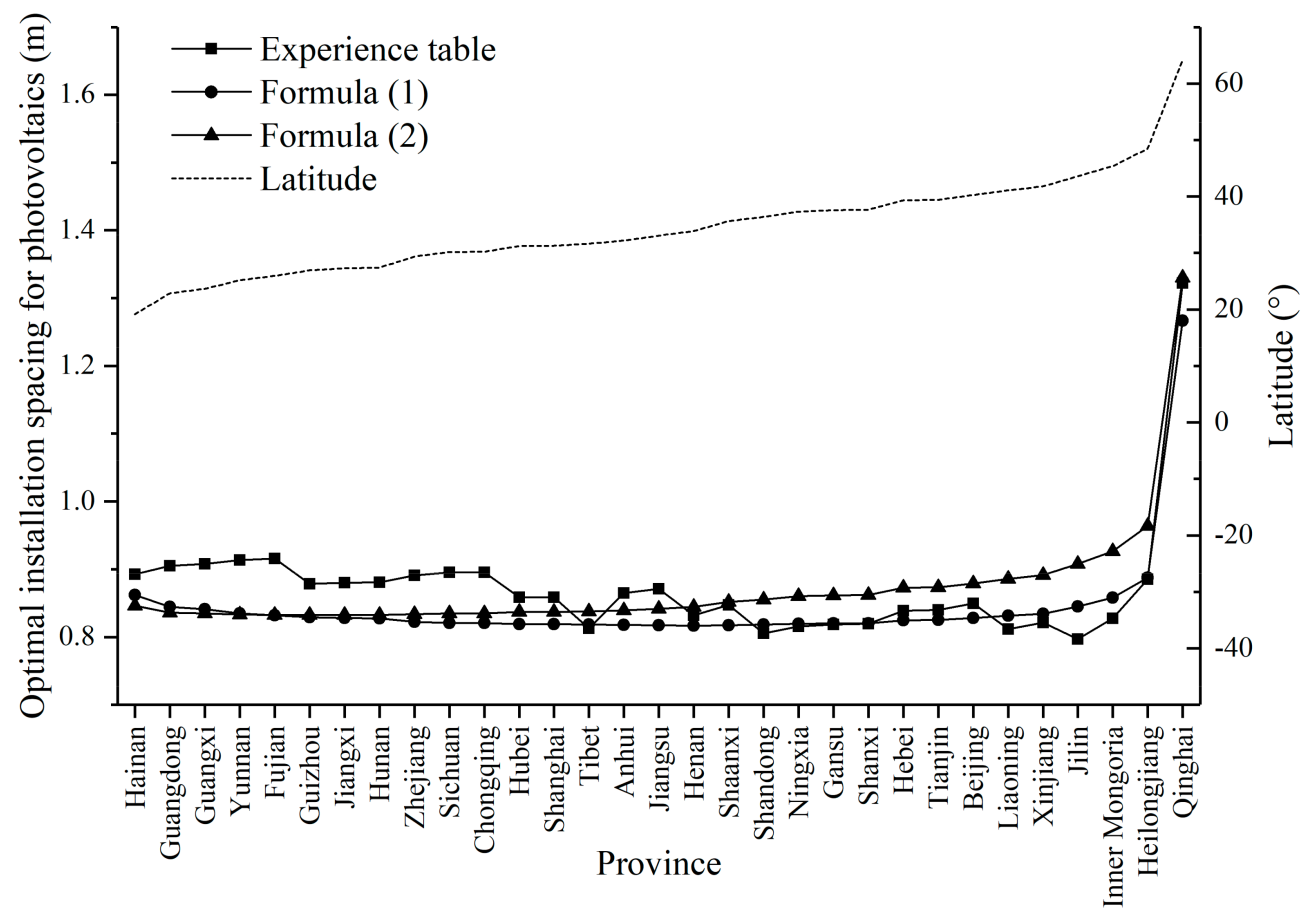

Figure 8. Comparison of the best installation spacing in various provinces and cities. 
Judging from the overall change trend of the optimal installation inclination angles of photovoltaics in different provinces and cities in Figure 8, the final optimal installation spacing calculated by different methods is not much different, and it has a small impact on the subsequent calculations. Therefore, the relevant calculations in the following chapters use the data calculated by Formula (2).

\subsubsection{Roof Photovoltaic Effective Power Generation Area}

In urban buildings, the installation of photovoltaic modules on the roof will be subject to many restrictions and influences other than photovoltaic panels. In order to calculate the effective photovoltaic power generation area of the roof, this section introduces the available coefficient $\eta_{a}$ to describe the solar energy installed on the roof of the building. The ratio of the effective power generation area of photovoltaic modules to the total floor area of the building. The value of the available coefficient $\eta_{a}$ needs to consider the influence of the following factors:

(1) Shadows caused by nearby buildings, trees, or other structures of some roofs themselves;

(2) Use of the roof area for other purposes, such as other household facilities installed on the roof, such as outdoor air conditioners;

(3) A part of the area needs to be reserved for the inspection and maintenance of photovoltaic modules by the staff.

(4) According to different geographical conditions, the available coefficient $\eta_{a}$ has different values in different literature studies, as shown in Table 2.

Table 2. Values of available coefficients $\eta_{a}$ for different documents.

\begin{tabular}{cc}
\hline Country and Region & Available Coefficients $\eta_{a}$ \\
\hline Taiwan [15] & 0.4 \\
Sweden [7] & 0.7 \\
Greece [28] & 0.5 \\
Israel [8] & 0.3 \\
\hline
\end{tabular}

From the data in Table 2, we can see that different cities have different levels of building density, and their available coefficients $\eta_{a}$ are inconsistent. However, the level of development of various cities in China is different, and their building density is also quite different. In order to reflect the above situation, in this section, certain classifications are made according to the development status of cities in different provinces, and the corresponding available coefficient $\eta_{a}$ is used for cities with different development conditions, as shown in Table 3:

Table 3. Values of the available coefficient $\eta_{a}$ of cities in different provinces in China.

\begin{tabular}{ccc}
\hline The Level of Development & Province City & Available Coefficient $\eta_{a}$ \\
\hline High & Beijing, Shanghai & 0.3 \\
\hline Higher & $\begin{array}{c}\text { Guangdong, Zhejiang, } \\
\text { Jiangsu, Shandong, } \\
\text { Chongqing, Tianjin }\end{array}$ & 0.4 \\
& $\begin{array}{c}\text { Heilongjiang, Jilin, Liaoning, } \\
\text { Shanxi, Sichuan, Hubei, } \\
\text { Hebei, Anhui, Fujian, Henan, } \\
\text { Hunan, Hainan, Guangxi, } \\
\text { Jiangxi, Shaanxi, Yunnan }\end{array}$ & 0.5 \\
& $\begin{array}{c}\text { Qinghai, Ningxia, Gansu, } \\
\text { Guizhou, Xinjiang, Tibet, } \\
\text { Inner Mongolia }\end{array}$ \\
\hline
\end{tabular}


On the other hand, considering that the panel area of photovoltaic panels cannot be fully used for power generation in actual use, the panel loss coefficient $\eta_{p}$ is quoted here, assuming that the panel loss (excluding power transmission and distribution loss) includes pollution $(2 \%)$, mismatch $(2 \%)$, wiring $(2 \%)$, connection $(0.5 \%)$, light-induced degradation $(1.5 \%)$, nameplate rating $(1 \%)$, availability $(0.5 \%)$ and shading $(0.5 \%)$.

Then the panel loss factor is $\eta_{p}=[1-(1-0.02) \times(1-0.02) \times(1-0.02) \times(1-0.005) \times$ $(1-0.015) \times(1-0.01) \times(1-0.005) \times(1-0.005)] \times 100 \%=9.6 \%$.

According to the previous calculation, the urban roof area $A_{P V}\left(\mathrm{~m}^{2}\right)$ and the optimal photovoltaic installation spacing can be obtained, and the effective roof photovoltaic power generation area $A_{B F}\left(\mathrm{~m}^{2}\right)$ can be calculated according to the following formula:

$$
A_{P V}=\frac{A_{B F}}{d_{\mathrm{opt}} l} \eta_{a}\left(1-\eta_{p}\right)
$$

where $d_{\text {opt }}$ is the optimal installation spacing $(\mathrm{m})$ for photovoltaics.

According to Formula (8), the effective rooftop photovoltaic power generation area of each province and city can be calculated as shown in Figure 9. It can be seen from Figure 9 that the total effective photovoltaic power generation area of cities across the country can reach 3.35 billion $\mathrm{m}^{2}$.

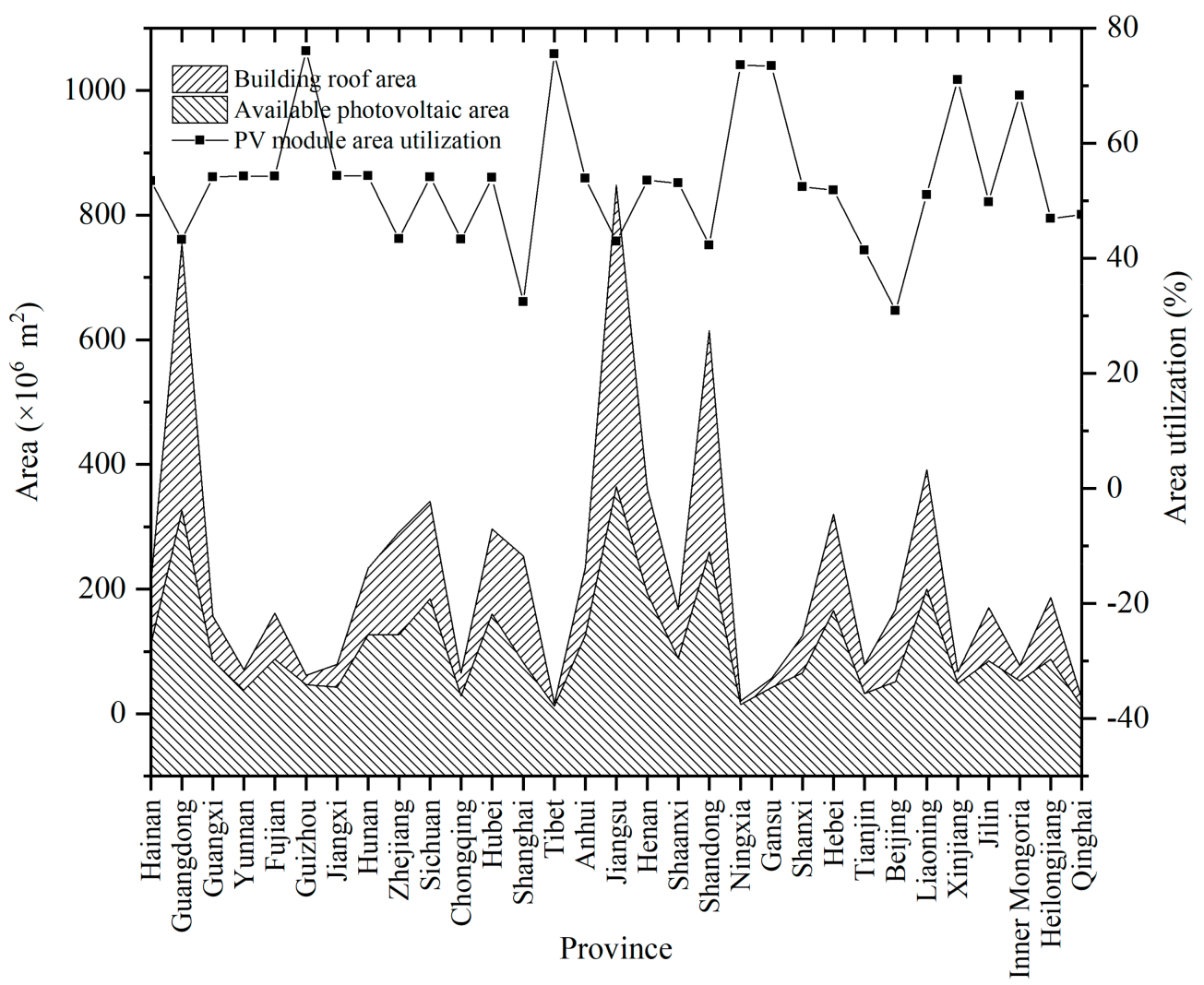

Figure 9. Areas of photovoltaic power generation in cities in different provinces in China.

\subsection{China's Urban Photovoltaic Power Generation Potential}

The potential of urban photovoltaic power generation can reflect the application value of photovoltaic system installation. The higher the potential of photovoltaic power generation, the higher the income from the development of the photovoltaic industry. Therefore, this chapter analyzes and calculates the photovoltaic power generation potential of various provinces and cities. In order to better express the potential of photovoltaic power generation, this chapter calculates and analyzes the installed photovoltaic capacity and the total annual photovoltaic power generation. 


\subsubsection{Urban PV Installed Capacity}

In order to estimate the annual installed capacity of provinces and cities, this section assumes that the performance parameters of installed and used monocrystalline silicon photovoltaic modules are shown in Table 4 according to the methods of photovoltaic related research [7].

Table 4. Performance parameters of monocrystalline silicon photovoltaic modules.

\begin{tabular}{cc}
\hline Characteristics of a PV Module (Jinko Solar, JKMS 350 M-72 V Maxim) \\
\hline Max power point voltage $(\mathrm{V})$ & 39.3 \\
Max power point current $(\mathrm{A})$ & 8.89 \\
Power temper. Coefficient $\left(\% /{ }^{\circ} \mathrm{C}\right)$ & -0.38 \\
Efficiency (Module area) $(\%)$ & 18.03 \\
Efficiency (Cells area) $(\%)$ & 20.5 \\
\hline
\end{tabular}

Assuming that all the photovoltaic panels in the above table are installed in each city, and the solar irradiance under the standard test conditions (STC) is used for power generation, and the power loss caused by a certain environment is considered, each province can be obtained. The formula for estimating the annual installed capacity of urban roofs is as follows:

$$
I_{P V}=A_{P V} \times G_{0} \times \eta_{P V} \times C_{0}
$$

where, $I_{P V}$ is photovoltaic installed capacity, $\mathrm{kW} ; G_{0}$ is solar irradiance under standard test conditions (STC), $\mathrm{kW} / \mathrm{m}^{2} ; \eta_{P V}$ is photovoltaic module power generation efficiency, taking $0.1803 ; C_{0}$ is taking into account temperature changes, component pollution, The comprehensive coefficient of transmission loss, inverter efficiency, battery charge and discharge compensation and other factors, the comprehensive coefficient of this photovoltaic system is set to $75 \%$.

According to Formula (9), the annual installed capacity of each province and city is calculated, and the calculation result is shown in Table 5. From the calculation results in Table 5, the total installed photovoltaic capacity of the country is $452.69 \mathrm{GW}$.

\subsubsection{Annual Power Generation of Urban Photovoltaic System}

The annual power generation of each province and city can be obtained by combining the photovoltaic installed capacity of each province and city calculated in the previous section with the solar radiation resources obtained in the previous statistics, as shown in Formula (10):

$$
E_{P V}=I_{P V} \times G
$$

where, $E_{P V}$ is photovoltaic power generation, $\mathrm{kWh} / \mathrm{a} ; G$ is the total solar radiation, $\mathrm{kWh} /\left(\mathrm{m}^{2} \cdot \mathrm{a}\right)$.

According to Formula (10), the annual power generation of cities in each province is calculated, and the calculation results are shown in Figure 10.

It can be seen from Figure 10 that in areas with high total solar radiation, the annual urban photovoltaic power generation capacity is not necessarily high. This is because China's solar energy resources are mainly concentrated in the northwest region, and the urban development level in these areas is low and can be used for the rooftop photovoltaic power generation space is small, so the annual power generation will be low. In addition, from the calculation results in Figure 10, if the rooftops of cities across the country are used for photovoltaic power generation, their annual photovoltaic power generation will be 671.9 billion $\mathrm{kWh}$. According to data released by the National Energy Administration, the total electricity consumption of urban and rural residents in the whole society in 2020 has reached 1094.9 billion $\mathrm{kWh}$ [29]. The annual photovoltaic power generation capacity provided by the roofs of urban buildings is about $60 \%$ of the total electricity consumption of residents. 
Table 5. Calculation of annual installed capacity of cities in different provinces.

\begin{tabular}{|c|c|c|}
\hline Province & $\begin{array}{c}\text { Photovoltaic Power } \\
\text { Generation Area } \\
\times 10^{6} \mathrm{~m}^{2}\end{array}$ & $\begin{array}{c}\text { Installed Capacity } \\
\text { GW }\end{array}$ \\
\hline Hainan & 111.89 & 15.1 \\
\hline Guangdong & 325.88 & 44.1 \\
\hline Guangxi & 84.78 & 11.5 \\
\hline Yunnan & 38.14 & 5.2 \\
\hline Fujian & 87.49 & 11.8 \\
\hline Guizhou & 46.65 & 6.3 \\
\hline Jiangxi & 42.95 & 5.8 \\
\hline Hunan & 126.54 & 17.1 \\
\hline Zhejiang & 126.52 & 17.1 \\
\hline Sichuan & 184.42 & 24.9 \\
\hline Chongqing & 28.24 & 3.8 \\
\hline Hubei & 160.25 & 21.7 \\
\hline Shanghai & 82.03 & 11.1 \\
\hline Tibet & 12.20 & 1.6 \\
\hline Anhui & 126.37 & 17.1 \\
\hline Jiangsu & 364.41 & 49.3 \\
\hline Henan & 193.48 & 26.2 \\
\hline Shaanxi & 88.80 & 12.0 \\
\hline Shandong & 259.88 & 35.1 \\
\hline Ningxia & 15.01 & 2.0 \\
\hline Gansu & 41.67 & 5.6 \\
\hline Shanxi & 65.90 & 8.9 \\
\hline Hebei & 165.75 & 22.4 \\
\hline Tianjin & 32.56 & 4.4 \\
\hline Beijing & 51.42 & 7.0 \\
\hline Liaoning & 199.83 & 27.0 \\
\hline Xinjiang & 47.81 & 6.5 \\
\hline Jilin & 84.93 & 11.5 \\
\hline Inner Mongoria & 52.74 & 7.1 \\
\hline Heilongjiang & 87.52 & 11.8 \\
\hline Qinghai & 11.67 & 1.6 \\
\hline
\end{tabular}

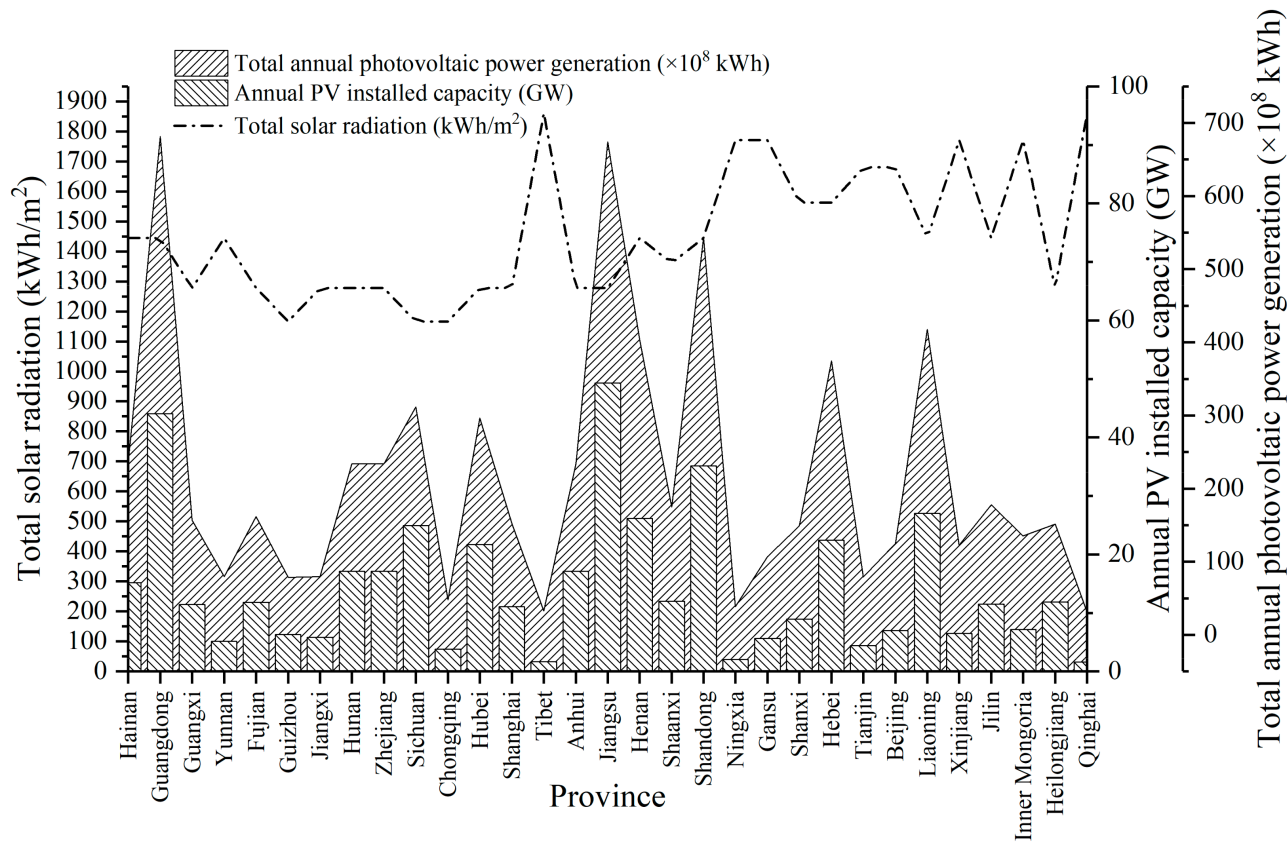

Figure 10. Photovoltaic power generation in cities in different provinces in China. 


\subsection{Economic Prediction and Analysis of Urban Photovoltaic Construction}

Judging from the calculation results in the previous chapters, there are a lot of resources available for photovoltaic power generation in Chinese urban buildings. If they can be used reasonably, they can alleviate the city's electrical power to a certain extent. Based on the previous calculations, the city can use photovoltaic resources to install and construct photovoltaic systems in all cities in mainland China. On this basis, we can predict and analyze the initial investment, operating costs, power generation income, and investment payback time required before and after the urban photovoltaic construction.

\subsubsection{Cost Analysis of Urban Photovoltaic Construction}

The construction components of urban photovoltaics are mainly divided into initial investment and operation and maintenance costs. Among them, the initial investment is mainly composed of important components of the photovoltaic power generation system, such as photovoltaic modules, inverters, and batteries. Among them, since in the calculation of photovoltaic power generation resources in Chapter 5, monocrystalline silicon photovoltaic modules are used, it is assumed that all monocrystalline silicon photovoltaic modules are used in the construction of urban photovoltaic systems.

Photovoltaic modules are the most important part of the photovoltaic system and account for a large part of the total cost of the system. At present, China is the world's largest manufacturer of photovoltaic modules. From 2009 to 2019, China accounted for more than $50 \%$ of the world's total output. Due to large-scale production, the cost of photovoltaic modules in China has dropped rapidly, from 38.00 yuan/watt in 2006 to 1.75 yuan/watt in 2019. Therefore, the scale effect of photovoltaic module production explains the reduction in the cost of photovoltaic power generation.

In order to facilitate the analysis of its investment cost, this section takes the current purchase price of important components of the photovoltaic system as the capital cost at the initial stage of system construction, and the replacement and maintenance of components required for the subsequent completion of the photovoltaic system as the system's later operating costs. The current economic data and main technical characteristics $[30,31]$ of the relevant components of the photovoltaic system are shown in Table 6.

Table 6. Economic cost and technical characteristics of each component cost of PV system.

\begin{tabular}{|c|c|c|c|c|}
\hline Components & $\begin{array}{c}\text { Capital } \\
\text { Yuan/kW }\end{array}$ & $\begin{array}{c}\text { Replacement } \\
\text { Yuan/kW }\end{array}$ & $\begin{array}{c}\text { O\&M } \\
\text { Yuan/(kW·Year) }\end{array}$ & $\begin{array}{l}\text { Lifetime } \\
\text { Year }\end{array}$ \\
\hline PV module ${ }^{1}$ & 1750 & 1750 & 22.16 & 25 \\
\hline Converter ${ }^{1}$ & 800 & 640 & 0 & 15 \\
\hline Battery $^{1}$ & 600 & 1857 & 0 & 5 \\
\hline
\end{tabular}

1 The cost data of photovoltaic modules is collected from the Solarzoom website [32], and the costs of other modules are collected from websites, such as Alibaba [33].

The design life of the photovoltaic system is 25 years, and the life of other components is less than this time, so in addition to the initial investment when calculating the total investment cost, the replacement cost of the battery and inverter should also be added. With the continuous development of the photovoltaic industry in recent years, the production process and product lines of various equipment have gradually matured, making the cost of various equipment reduce year by year. It can be assumed that in the next 25 years, the inverter price will be reduced by $20 \%$ after 15 years, and the battery will be reduced by $10 \%$ every 5 years. It can be calculated that during the 25 -year life cycle of the photovoltaic system, the total cost of the photovoltaic system construction is $6201 \mathrm{RMB}$ Yuan $/ \mathrm{kW}$. From this, it can be calculated that the total investment cost of the photovoltaic system in each province and city during 25 years of operation is 2807 billion yuan, as shown in Figure 11. 


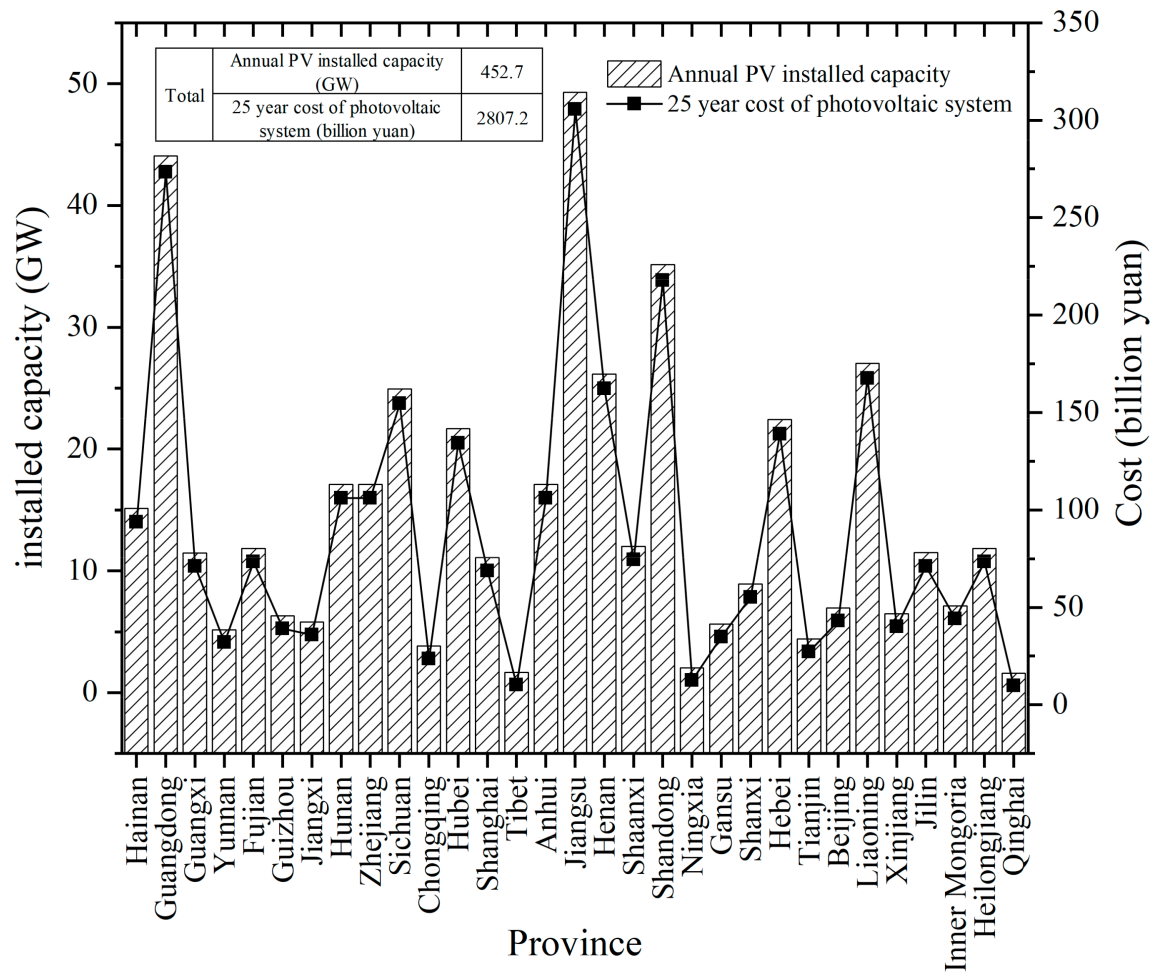

Figure 11. 25-year cost of photovoltaic system construction in various provinces.

\subsubsection{Urban Photovoltaic Construction Income and Return Time}

Although the initial investment and maintenance costs of installing photovoltaic systems on urban buildings are relatively high, the photovoltaic system can use solar power to provide electricity for the building during subsequent operations, which can save the overall energy consumption of the building. Therefore, after the operation of the urban building photovoltaic system, the corresponding economic benefits can be obtained through three aspects. The first aspect is that since China began to implement the net metering policy in 2013, residential users who invest in the construction of distributed photovoltaic systems and adopt the "spontaneous self-use, remaining online" model can use photovoltaic system power generation to offset the original consumption of the market grid electricity, thereby saving electricity bills.

The second aspect is government subsidies for distributed photovoltaic system power generation. In 2013, the Chinese government implemented a net metering subsidy of 0.42 yuan $/ \mathrm{kWh}$ for distributed photovoltaic power generation. After that, with the decline in the cost of photovoltaic power generation and the rapid development of the photovoltaic industry, on 2 April 2020, the National Development and Reform Commission issued the "About The 2020 Notice on Issues Related to the On-grid Tariff Policy for Photovoltaic Power Generation stipulates: The subsidy standard for industrial and commercial distributed photovoltaic projects under the mode of "self-generated and self-use, surplus electricity on the grid" model is 0.05 yuan $/ \mathrm{kWh}$; the subsidy standard for household distributed photovoltaic power is adjusted to 0.08 yuan $/ \mathrm{kWh}$ yuan. In the third aspect, the Chinese government requires power grid companies to purchase renewable energy power based on local coal-fired benchmark tariffs. Therefore, users of distributed photovoltaic systems can also sell excess power to the grid and profit from it. Therefore, the profit that users who invest in distributed photovoltaic systems can get can be calculated using the following formula:

$$
R=\left(E_{\text {load }}+E_{\text {grid }}\right) \times P_{\text {subsidy }}+E_{\text {grid }} \times P_{\text {grid }}+E_{\text {load }} \times P_{\text {local }}
$$


where, $R$ is the total annual income of users investing in a distributed photovoltaic system, yuan/year; $E_{\text {load }}$ is the electricity consumption of users, $\mathrm{kWh} /$ year; $E_{\text {grid }}$ is the surplus electricity sold to the State Grid, kwh/year; $P_{\text {subsidy }}$ is the government's subsidy for the generation of a distributed photovoltaic system, yuan $/ \mathrm{kWh}, P_{\text {local }}$ is the local residential electricity price of users, yuan $/ \mathrm{kWh} ; P_{\text {grid }}$ is the benchmark electricity price in China, yuan $/ \mathrm{kWh}$.

Among them, in 2020, the benchmark electricity prices for photovoltaic power generation in Category I III resource areas that will be included in the scope of national financial subsidies will be 0.35 yuan $/ \mathrm{kWh}, 0.4$ yuan $/ \mathrm{kWh}$, and 0.49 yuan $/ \mathrm{kWh}$ respectively. In 2020, China's residential electricity price varies from province to province according to local conditions, as shown in Figure 12.

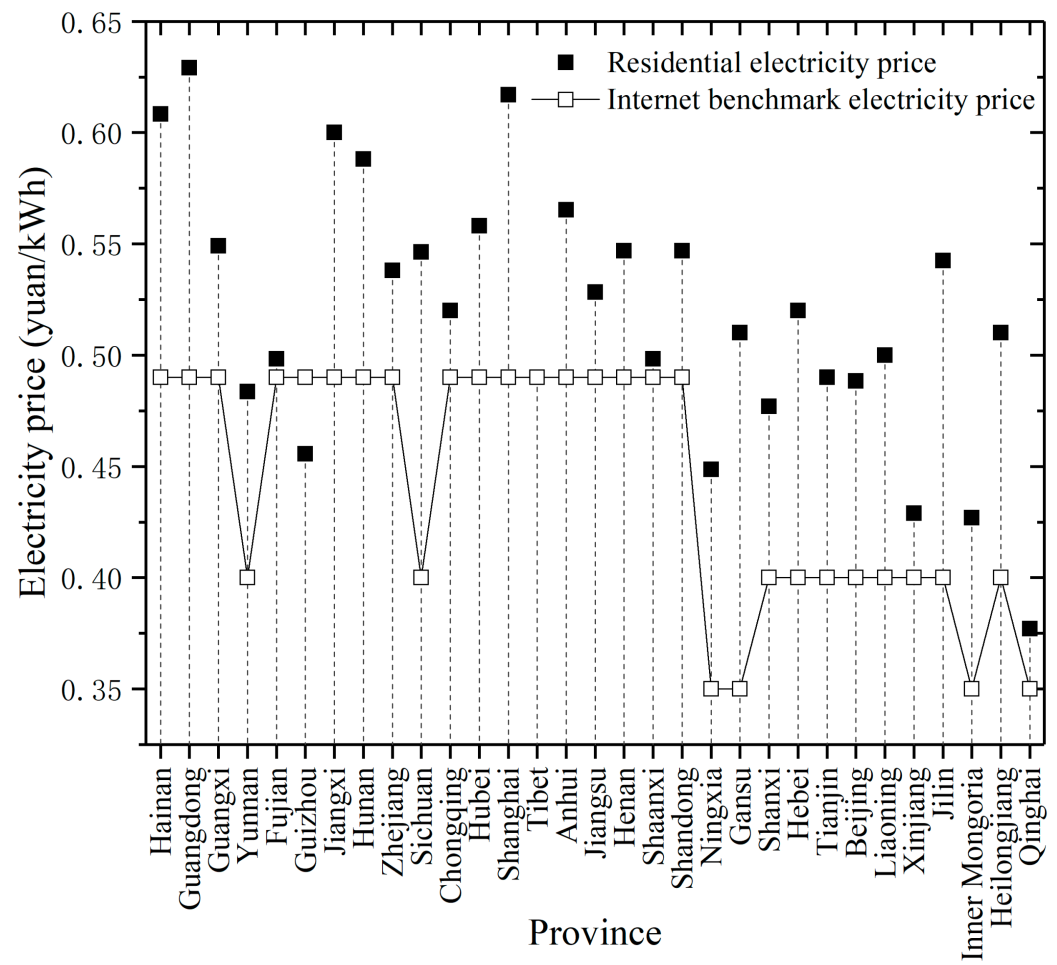

Figure 12. China's residential electricity price and photovoltaic on-grid price in 2020.

There are two main directions for the power generated by distributed photovoltaic systems: users use it by themselves and sell it to the local power grid. The power resources used by users are composed of two parts, one is the power generated by photovoltaic modules. When the power generated by photovoltaic modules is not enough to support the use of users, insufficient power will be purchased from the local power grid. Xinyu Jia et al. [34] selected five typical cities of Chongqing, Guangzhou, Beijing, Yushu and Lhasa as the research objects from five regions with different solar radiation levels in China and analyzed the benefits of domestic distributed photovoltaic system in China. The power consumption of actual residential users was simulated by inputting the photovoltaic system configuration in Homer software. The simulation results show that, In terms of power consumption, about $30 \%$ of the photovoltaic systems in the five cities sell to the local power grid, which means that $70 \%$ of the power generated by the photovoltaic system is used by users themselves. In this study, $70 \%$ of the annual average power generation is also taken as the self-consumption in the first year, and the remaining $30 \%$ is sold to the local power grid in the first year. Based on this, the user profit is calculated according to Formula (11).

With the increase of the operation time of the photovoltaic system, the aging and wear of related components will lead to the decrease of power generation year by year. Therefore, 
when calculating the economic benefits, the annual power generation of photovoltaic modules is set to be reduced by $5 \%$ per year. At the same time, the development and popularization of the photovoltaic industry will also lead to the decrease of photovoltaic power generation subsidies and grid benchmark price year by year, and the reduction ratio is set to $5 \%$; Economic development will also lead to the increase of electricity price and electricity consumption of residential users year by year. At this time, the proportion of electricity used by users in the photovoltaic system will also increase year by year, and the growth rate is set at $5 \%$. In addition, since the purpose of the national implementation of photovoltaic power generation subsidies is to stimulate the application and development of the photovoltaic industry, and the photovoltaic system has developed rapidly in recent years and has been widely used in many provinces, the photovoltaic subsidies may be canceled in the next few years. Therefore, the subsidy income will become a part of the income with great uncertainty. Therefore, this paper also calculates the total income of the users who install the photovoltaic system when the subsidy income is not included. Table 7 shows the photovoltaic system income calculated by taking Jiangsu Province as an example.

Table 7. 25-year income of urban photovoltaic installations in Jiangsu Province.

\begin{tabular}{|c|c|c|c|c|c|c|c|c|}
\hline Year & $\begin{array}{c}\text { Power } \\
\text { Generation } \\
\text { Billion kWh }\end{array}$ & $\begin{array}{l}\quad \text { Self- } \\
\text { Consumption } \\
\text { Billion kWh }\end{array}$ & $\begin{array}{c}\text { Electricity } \\
\text { Sales Billion } \\
\text { kWh }\end{array}$ & $\begin{array}{c}\text { Subsidized } \\
\text { Price } \\
\text { Yuan/kWh }\end{array}$ & $\begin{array}{l}\text { Resident } \\
\text { Electricity Price } \\
\text { Yuan/kWh }\end{array}$ & $\begin{array}{c}\text { Feed-in } \\
\text { Tariff } \\
\text { Yuan/kWh }\end{array}$ & $\begin{array}{c}\text { Income } \\
\text { (Including } \\
\text { Subsidies) } \\
\text { Billion Yuan }\end{array}$ & $\begin{array}{c}\text { Income } \\
\text { (Excluding } \\
\text { Subsidies) } \\
\text { Billion Yuan }\end{array}$ \\
\hline 1 & 67.40 & 47.18 & 20.22 & 0.08 & 0.5283 & 0.49 & 40.22 & 34.83 \\
\hline 2 & 64.03 & 44.82 & 19.21 & 0.08 & 0.5547 & 0.47 & 78.90 & 68.64 \\
\hline 3 & 60.83 & 42.58 & 18.25 & 0.07 & 0.5825 & 0.44 & 116.16 & 101.51 \\
\hline 4 & 57.79 & 40.45 & 17.34 & 0.07 & 0.6116 & 0.42 & 152.14 & 133.53 \\
\hline 5 & 54.90 & 38.43 & 16.47 & 0.07 & 0.6422 & 0.40 & 186.97 & 164.78 \\
\hline 6 & 52.15 & 36.51 & 15.65 & 0.06 & 0.6743 & 0.38 & 220.75 & 195.33 \\
\hline 7 & 49.55 & 34.68 & 14.86 & 0.06 & 0.7080 & 0.36 & 253.57 & 225.23 \\
\hline 8 & 47.07 & 32.95 & 14.12 & 0.06 & 0.7434 & 0.34 & 285.52 & 254.56 \\
\hline 9 & 44.71 & 31.30 & 13.41 & 0.05 & 0.7805 & 0.33 & 316.69 & 283.35 \\
\hline 10 & 42.48 & 29.74 & 12.74 & 0.05 & 0.8196 & 0.31 & 347.13 & 311.66 \\
\hline 11 & 40.35 & 28.25 & 12.11 & 0.05 & 0.8605 & 0.29 & 376.93 & 339.52 \\
\hline 12 & 38.34 & 26.84 & 11.50 & 0.05 & 0.9036 & 0.28 & 406.12 & 366.97 \\
\hline 13 & 36.42 & 25.49 & 10.93 & 0.04 & 0.9488 & 0.26 & 434.78 & 394.05 \\
\hline 14 & 34.60 & 24.22 & 10.38 & 0.04 & 0.9962 & 0.25 & 462.94 & 420.79 \\
\hline 15 & 32.87 & 23.01 & 9.86 & 0.04 & 1.0460 & 0.24 & 490.64 & 447.21 \\
\hline 16 & 31.23 & 21.86 & 9.37 & 0.04 & 1.0983 & 0.23 & 517.93 & 473.35 \\
\hline 17 & 29.66 & 20.77 & 8.90 & 0.04 & 1.1532 & 0.22 & 544.85 & 499.21 \\
\hline 18 & 28.18 & 19.73 & 8.45 & 0.03 & 1.2109 & 0.20 & 571.41 & 524.83 \\
\hline 19 & 26.77 & 18.74 & 8.03 & 0.03 & 1.2714 & 0.19 & 597.65 & 550.22 \\
\hline 20 & 25.43 & 17.80 & 7.63 & 0.03 & 1.3350 & 0.18 & 623.59 & 575.40 \\
\hline 21 & 24.16 & 16.91 & 7.25 & 0.03 & 1.4017 & 0.18 & 649.27 & 600.38 \\
\hline 22 & 22.95 & 16.07 & 6.89 & 0.03 & 1.4718 & 0.17 & 674.69 & 625.18 \\
\hline 23 & 21.81 & 15.26 & 6.54 & 0.03 & 1.5454 & 0.16 & 699.88 & 649.80 \\
\hline 24 & 20.72 & 14.50 & 6.21 & 0.02 & 1.6227 & 0.15 & 724.86 & 674.27 \\
\hline 25 & 19.68 & 13.78 & 5.90 & 0.02 & 1.7038 & 0.14 & 749.63 & 698.59 \\
\hline
\end{tabular}

It can be seen from Figure 11 that the initial investment of the photovoltaic system in Jiangsu Province is 305.6 billion yuan. However, it can be seen from Table 7 that if the subsidies are included, the cumulative income of the distributed photovoltaic system installed in urban construction in Jiangsu Province in the ninth year of operation is 316.7 billion yuan, which exceeds the initial investment. At this time, the cost of the system has been recovered, and the cumulative income in 25 years reached 749.6 billion yuan, which is 2.45 times the initial investment. If the subsidy is not included, the capital will be recovered in the 10th year. The accumulated income in the 25th year is 698.6 billion yuan, which is 2.28 times the initial investment. According to the calculation results of Jiangsu Province, although it takes about 10 years for the PV system to cost back and forth, in its 25 -year work cycle, its cumulative revenue is still very considerable. We use the same 
method to calculate the total income and payback time of other provinces in China. The results are shown in Table 8.

Table 8. The total revenue and payback time of PV operation in cities in each Province.

\begin{tabular}{|c|c|c|c|c|}
\hline Province & $\begin{array}{c}\text { Cumulative Total Income } \\
\text { (Including Subsidies) } \\
\text { Billion Yuan }\end{array}$ & $\begin{array}{c}\text { Payback Time } \\
\text { (Including Subsidies) } \\
\text { Year }\end{array}$ & $\begin{array}{c}\text { Cumulative Total Income } \\
\text { (Excluding Subsidies) } \\
\text { Billion Yuan }\end{array}$ & $\begin{array}{c}\text { Payback Time } \\
\text { (Excluding Subsidies) } \\
\text { Year }\end{array}$ \\
\hline Hainan & 291.97 & 7 & 274.25 & 8 \\
\hline Guangdong & 874.49 & 7 & 822.88 & 8 \\
\hline Guangxi & 179.94 & 9 & 168.06 & 10 \\
\hline Yunnan & 80.61 & 9 & 74.57 & 10 \\
\hline Fujian & 171.74 & 10 & 159.48 & 11 \\
\hline Guizhou & 77.89 & 11 & 71.92 & 13 \\
\hline Jiangxi & 98.03 & 8 & 92.01 & 9 \\
\hline Hunan & 284.04 & 8 & 266.31 & 9 \\
\hline Zhejiang & 264.13 & 8 & 246.40 & 10 \\
\hline Sichuan & 348.00 & 10 & 324.41 & 11 \\
\hline Chongqing & 52.37 & 12 & 48.76 & 13 \\
\hline Hubei & 344.60 & 9 & 322.15 & 10 \\
\hline Shanghai & 191.59 & 8 & 180.10 & 9 \\
\hline Tibet & 34.41 & 6 & 31.92 & 7 \\
\hline Anhui & 274.65 & 9 & 256.95 & 10 \\
\hline Jiangsu & 749.64 & 9 & 698.59 & 10 \\
\hline Henan & 462.72 & 8 & 432.08 & 9 \\
\hline Shaanxi & 185.68 & 9 & 172.43 & 10 \\
\hline Shandong & 621.50 & 8 & 580.35 & 9 \\
\hline Ningxia & 36.06 & 8 & 33.15 & 9 \\
\hline Gansu & 111.22 & 8 & 103.13 & 9 \\
\hline Shanxi & 148.98 & 8 & 137.69 & 9 \\
\hline Hebei & 402.08 & 8 & 373.69 & 9 \\
\hline Tianjin & 80.92 & 8 & 74.92 & 9 \\
\hline Beijing & 127.43 & 8 & 117.96 & 9 \\
\hline Liaoning & 433.93 & 9 & 402.29 & 10 \\
\hline Xinjiang & 112.49 & 8 & 103.21 & 9 \\
\hline Jilin & 197.21 & 8 & 183.76 & 9 \\
\hline Inner Mongoria & 121.73 & 8 & 111.49 & 9 \\
\hline Heilongjiang & 159.64 & 11 & 148.18 & 12 \\
\hline Qinghai & 25.64 & 8 & 23.26 & 10 \\
\hline
\end{tabular}

It can be seen from Table 8 that the investment payback period of photovoltaic systems in various provinces and cities in China is mostly 8-9 years, and the operation time of the photovoltaic system is 25 years. Therefore, the construction of photovoltaic systems on the roofs of Chinese cities has more than half of the operating life due to pure income, which has high investment and construction value, and even if the system is rebuilt after its operating life is reached, there will be more capital reserve space, which has high reliability.

\section{Conclusions}

This paper uses geographic information system (GIS) technology to count the available photovoltaic area of urban building roofs in mainland China and uses this as a basis to study the power generation potential and economic benefit evaluation of urban building roof photovoltaic systems in mainland China. According to the previous article According to the statistical calculation results, the following conclusions can be obtained:

The usable area of photovoltaic roofs of urban buildings in mainland China has reached 3.35 billion $\mathrm{m}^{2}$. The PV installed capacity has reached $452.69 \mathrm{GW}$. If the national urban roofs are used for photovoltaic power generation, the annual photovoltaic power generation capacity will reach 671.992 billion $\mathrm{kWh}$, accounting for about $61 \%$ of the annual power consumption of China's whole society in 2020. Using only the photovoltaic power generation resources on the roofs of urban buildings can bear more than half of the total electricity consumption in cities and rural areas. It can be seen that the development potential of urban building photovoltaic is great. If the Chinese government strengthens the construction of urban building photovoltaic systems in the future urban construction 
planning, it can greatly alleviate the pressure on the urban power grid at the present stage and greatly accelerate the process of carbon peak and carbon neutralization in China.

On the other hand, although the initial investment of roof distributed photovoltaic system is large, solar energy is renewable energy. With the gradual increase of the construction of urban roof photovoltaic systems, the investment can be recovered in a short time (8-10 years). Moreover, in the effective life of the follow-up photovoltaic system, it will bring greater economic benefits, which is more than two times the initial investment. From the economic calculation results of urban building photovoltaic system, the construction of urban building photovoltaic system has high economic benefits. This feature can greatly stimulate the enthusiasm of urban managers and residents to build photovoltaic buildings, so as to promote the overall progress of photovoltaic construction in China.

Generally speaking, the cities in mainland China are densely built and the ground is severely blocked. However, they have a very high advantage in the development of photovoltaic systems on the roofs of buildings. However, due to the relatively high investment in photovoltaic systems, the actual development and utilization of the existing buildings in the cities in the transformation cannot be fully utilized. Therefore, in order to further promote the process of social carbon peaking and carbon neutrality in China, the construction of urban photovoltaic systems is an inevitable and requires the attention of relevant departments.

In this study, the urban building facade area and roof area are statistically calculated, but there is no further research and calculation on the photovoltaic installation potential on the building facade. Therefore, in future research on urban building photovoltaic, the application potential of building facade photovoltaic can be analyzed based on the building facade area calculated in this study. In addition, in the economic analysis of future building photovoltaic system construction, the impact of the reduction of photovoltaic system operation and maintenance cost caused by the development of photovoltaic technology is not considered. Therefore, the investment return period of the photovoltaic system calculated in this study is too long, which can be taken into account in the subsequent economic analysis of urban photovoltaic, so as to obtain a more accurate result.

Author Contributions: Writing-original draft, W.Z.; validation, F.H.; data curation, W.Z.; formal analysis, F.H.; project administration, K.M.; software, C.L.; writing-review and editing, Z.P. All authors have read and agreed to the published version of the manuscript.

Funding: This study was supported by the National Natural Science Foundation of China (Grant No. 51908287) and the National Natural Science Foundation of Jiangsu Province (Grant No. BK20180484).

Institutional Review Board Statement: Not applicable.

Informed Consent Statement: Not applicable.

Data Availability Statement: Not applicable.

Acknowledgments: This study was supported by the National Natural Science Foundation of China (Grant No. 51908287) and the National Natural Science Foundation of Jiangsu Province (Grant No. BK20180484).

Conflicts of Interest: The authors declare no conflict of interest.

\section{References}

1. IPCC. Summary for Policymakers. Available online: https://www.ipcc.ch/sr15/chapter/spm/ (accessed on 10 April 2021).

2. Mata, E.; Korpal, A.K.; Cheng, S.H.; Navarro, J.P.J.; Filippidou, F.; Reyna, J.; Wang, R. A map of roadmaps for zero and low energy and carbon buildings worldwide. Environ. Res. Lett. 2020, 15, 19. [CrossRef]

3. International Energy Agency. World Energy Outlook 2019 Executive Summary. Available online: https://www.iea.org/reports / world-energy-outlook-2019 (accessed on 10 April 2021).

4. Robati, M.; Oldfield, P.; Nezhad, A.A.; Carmichael, D.G.; Kuru, A. Carbon value engineering: A framework for integrating embodied carbon and cost reduction strategies in building design. Build. Environ. 2021, 192, 17. [CrossRef]

5. Mohajeri, N.; Upadhyay, G.; Gudmundsson, A.; Assouline, D.; Kampf, J.; Scartezzini, J.L. Effects of urban compactness on solar energy potential. Renew. Energy 2016, 93, 469-482. [CrossRef] 
6. Yi, S. The Spatial Distribution of Solar Energy and the Comprehensive Potential Evaluation of Regional Exploitation and Utilization in China. Master's Thesis, Lanzhou University, Lanzhou, China, 2014.

7. Yang, Y.; Campana, P.E.; Stridh, B.; Yan, J.Y. Potential analysis of roof-mounted solar photovoltaics in Sweden. Appl. Energy 2020, 279, 14. [CrossRef]

8. Vardimon, R. Assessment of the potential for distributed photovoltaic electricity production in Israel. Renew. Energy 2011, 36, 591-594. [CrossRef]

9. Shafique, M.; Luo, X.W.; Zuo, J. Photovoltaic-green roofs: A review of benefits, limitations, and trends. Solar Energy 2020, 202, 485-497. [CrossRef]

10. Koo, C.; Hong, T.; Park, H.S.; Yun, G. Framework for the analysis of the potential of the rooftop photovoltaic system to achieve the net-zero energy solar buildings. Prog. Photovolt. 2014, 22, 462-478. [CrossRef]

11. Notice on Submitting the Pilot Scheme of Roof Distributed Photovoltaic Development in the Whole County (City, District). Available online: http:/ / zfxxgk.nea.gov.cn/index.htmt (accessed on 30 July 2021).

12. 11th Province Shanxi Province Issued the Policy of Promoting Distributed Photovoltaic in the Whole County (Report before 9 July) Available online: https:/ / baijiahao.baidu.com/s?id=1703804914999411688\&wfr=spider\&for=pc (accessed on 30 July 2021).

13. Zhang, W.J.; Zhao, Y.Q.; Huang, F.C.; Zhong, Y.H.; Zhou, J.W. Forecasting the Energy and Economic Benefits of Photovoltaic Technology in China's Rural Areas. Sustainability 2021, 13, 22. [CrossRef]

14. Shen, X.; Zhaojian, H.; Jianghua, W.; Mendis, T.; Jing, H. Evaluation of photovoltaic potential by urban block typology: A case study of Wuhan, China. Renew. Energy Focus 2019, 29, 141-147.

15. Yue, C.D.; Huang, G.R. An evaluation of domestic solar energy potential in Taiwan incorporating land use analysis. Energy Policy 2011, 39, 7988-8002. [CrossRef]

16. "A Very Encouraging Step" —China Strives to Achieve Carbon Neutrality by 2060. Available online: https://www.ccdi.gov.cn/ yaowen/202009/t20200926_226245.html (accessed on 30 July 2021).

17. Building Contour Vector Data of 62 Cities in China. Available online: https://www.sohu.com/a/324288814_100020239 (accessed on 30 November 2021).

18. Cao, Y. Research on automatic calculation method of building area indices of urban planning. Sci. Surv. Mapp. 2017, 42, 75-79.

19. Wang, Y. Energy Consumption Characteristic Model and Strength Dynamic Characteristic Analysis of Civil Buildings in China and Provinces. Master's Thesis, Beijing University of Civil Engineering and Architecture, Beijing, China, 2019.

20. Liang, J.; Zhang, W.; Tian, X.; Zhang, J.; Zhou, J. Prediction of Heating Energy Consumption and Analysis of Energy Saving Potential in Northern Urban Areas of China. In Proceedings of the 2020 2nd International Conference on Environment, Resources and Energy Engineering, Singapore, 24-26 July 2020; Volume 566.

21. Niu, Q. GIS Based Large Scale Modeling and Archiving of Buildings in Historic Conservation Area: Take Luojia Hill Historic Conservation Area for Example. In Progress in Industrial and Civil Engineering, Pts. 1-5; Yang, W.J., Li, Q.S., Eds.; Trans Tech Publications Ltd: Stafa-Zurich, Switzerland, 2012; Volume 204-208, pp. 3553-3556.

22. Freitas, S.; Catita, C.; Redweik, P.; Brito, M.C. Modelling solar potential in the urban environment: State-of-the-art review. Renew. Sustain. Energy Rev. 2015, 41, 915-931. [CrossRef]

23. Faisal, K.; Shaker, A.; Habbani, S. Modelling the Relationship between the Gross Domestic Product and Built-Up Area Using Remote Sensing and GIS Data: A Case Study of Seven Major Cities in Canada. ISPRS Int. Geo-Inf. 2016, 5, 16.

24. Zhou, R.; Li, Y.-H.; Hu, Y.-M.; Xi, F.-M.; Shan, T.; He, H.-S.; Liu, M.; Wang, J.-N. Spatiotemporal expansion of urban and rural built-up areas in Shenyang City: An analysis based on remote sensing and GIS technology. Yingyong Shengtai Xuebao 2009, 20, 2446-2454. [PubMed]

25. National Data. Available online: https:/ / data.stats.gov.cn/ (accessed on 30 November 2021).

26. Chang, T.P. The Sun's apparent position and the optimal tilt angle of a solar collector in the northern hemisphere. Solar Energy 2009, 83, 1274-1284. [CrossRef]

27. Martin-Chivelet, N. Photovoltaic potential and land-use estimation methodology. Energy 2016, 94, 233-242. [CrossRef]

28. Karteris, M.; Slini, T.; Papadopoulos, A.M. Urban solar energy potential in Greece: A statistical calculation model of suitable built roof areas for photovoltaics. Energy Build. 2013, 62, 459-468. [CrossRef]

29. China Electric Power Industry Statistics in 2020. Available online: http://www.nea.gov.cn/2021-01/20/c_139683739.htm (accessed on 20 September 2021).

30. Zou, H.Y.; Du, H.B.; Brown, M.A.; Mao, G.Z. Large-scale PV power generation in China: A grid parity and techno-economic analysis. Energy 2017, 134, 256-268. [CrossRef]

31. Adefarati, T.; Bansal, R.C. Reliability and economic assessment of a microgrid power system with the integration of renewable energy resources. Appl. Energy 2017, 206, 911-933. [CrossRef]

32. SolarZoom. Price Monitoring of Photovoltaic Industry China. Available online: http://m.solarzoom.com/article-152517-1.html (accessed on 10 October 2021).

33. Alibaba. Purchase and Wholesale Trade. Available online: https://www.1688.com/ (accessed on 10 October 2021).

34. Jia, X.Y.; Du, H.B.; Zou, H.Y.; He, G. Assessing the effectiveness of China's net-metering subsidies for household distributed photovoltaic systems. J. Clean Prod. 2020, 262, 9. [CrossRef] 